\title{
Chemical Mediation of Oviposition by Anopheles Mosquitoes: a Push-Pull System Driven by Volatiles Associated with Larval Stages
}

\author{
Bruce Schoelitsz $^{1,2} \cdot$ Victor Mwingira ${ }^{1,3} \cdot$ Leonard E. G. Mboera $^{4} \cdot$ Hans Beijleveld ${ }^{1,5} \cdot$ Constantianus J. M. Koenraadt $^{1}$. \\ Jeroen Spitzen ${ }^{1}$. Joop J. A. van Loon ${ }^{1}$ - Willem Takken ${ }^{1}$
}

Received: 9 February 2020 / Revised: 15 March 2020 / Accepted: 19 March 2020 / Published online: 2 April 2020

(C) The Author(s) 2020

\begin{abstract}
The oviposition behavior of mosquitoes is mediated by chemical cues. In the malaria mosquito Anopheles gambiae, conspecific larvae produce infochemicals that affect this behavior. Emanations from first instar larvae proved strongly attractive to gravid females, while those from fourth instars caused oviposition deterrence, suggesting that larval developmental stage affected the oviposition choice of the female mosquito.

We examined the nature of these chemicals by headspace collection of emanations of water in which larvae of different stages were developing. Four chemicals with putative effects on oviposition behavior were identified: dimethyldisulfide (DMDS) and dimethyltrisulfide (DMTS) were identified in emanations from water containing fourth instars; nonane and 2,4-pentanedione (2,4-PD) were identified in emanations from water containing both first and fourth instars. Dual-choice oviposition studies with these compounds were done in the laboratory and in semi-field experiments in Tanzania.

In the laboratory, DMDS and DMTS were associated with oviposition-deterrent effects, while results with nonane and 2,4-PD were inconclusive. In further studies DMDS and DMTS evoked egg retention, while with nonane and 2,4-PD 88\% and 100\% of female mosquitoes, respectively, laid eggs. In dual-choice semi-field trials DMDS and DMTS caused oviposition deterrence, while nonane and 2,4-PD evoked attraction, inducing females to lay more eggs in bowls containing these compounds compared to the controls. We conclude that oviposition of An. gambiae is mediated by these four infochemicals associated with conspecific larvae, eliciting either attraction or deterrence. High levels of egg retention occurred when females were exposed to chemicals associated with fourth instar larvae.
\end{abstract}

Keywords Anopheles coluzzii $\cdot$ An. gambiae s.s. $\cdot$ Malaria $\cdot$ Mosquito $\cdot$ Oviposition $\cdot$ Dimethyldisulfide $\cdot$ Dimethyltrisulfide $\cdot$ Nonane $\cdot 2$,4-pentanedione $\cdot$ Behavior

Electronic supplementary material The online version of this article (https://doi.org/10.1007/s10886-020-01175-5) contains supplementary material, which is available to authorized users.

Willem Takken

willem.takken@wur.nl

1 Laboratory of Entomology, Wageningen University and Research, P.O. Box 16, 6700 AA, Wageningen, The Netherlands

2 HAS University of Applied Sciences, Onderwijsboulevard 221, 5223 DE, 's-Hertogenbosch, The Netherlands

3 National Institute for Medical Research, Amani Research Centre, P.O. Box 81, Muheza, Tanzania

4 SACIDS Foundation for One Health, Sokoine University of Agriculture, P.O. Box 3297, Morogoro, Chuo Kikuu, Tanzania

5 Environmental Technology, Wageningen University \& Research, Bornsesteeg 59B, 6708 PD Wageningen, The Netherlands

\section{Introduction}

Assessment and selection of suitable oviposition habitats is important for the life history of mosquitoes (Bentley and Day 1989). Several studies have shown that the selection of oviposition sites by mosquitoes is influenced by chemicals. Culex quinquefasciatus Say, for instance, is known to be attracted to a variety of volatiles from breeding sites, including oviposition pheromones produced by conspecific eggs (Otieno et al. 1988) and compounds originating from organic material such as grass infusions and the compound skatole (Mboera et al. 2000a). It has since been shown that odor blends can be used to manipulate egg-laying females of $C x$. quinquefasciatus and are therefore suitable for monitoring and control of this species (Mboera et al. 2000b). Several Aedes species also use chemical cues originating from microbes to identify oviposition sites (Allan and Kline 1995; Santana et al. 2006; Lindh et al. 2008). 
The African malaria mosquito Anopheles gambiae Giles sensu stricto (hence referred to as An. gambiae) is known to be affected by volatiles from micro-organisms in soil and water of breeding sites (Huang et al. 2006; Sumba et al. 2004) and is attracted by water from natural oviposition sites (Herrera-Varela et al. 2014; Okal et al. 2013; Sumba et al. 2008). In addition, female mosquitoes of this species show an olfactory-based preference for oviposition sites in which larvae of the same regional population of An. gambiae have developed (Ogbunugafor and Sumba 2008). Furthermore, gravid females are repelled by emanations from breeding sites in which third and fourth instars were developing (Suh et al. 2016). The repellence caused by larvae on egg-laying behavior of gravid females has also been observed to be affected by the density of larvae (Munga et al. 2006). A low density of young larvae had a positive effect on oviposition, whereas high densities of older larvae negatively affected oviposition (Sumba et al. 2008). More recently, the effects of larval stage and density have been studied in greater detail (Mwingira et al. 2019), suggesting a production of chemical compounds that affect oviposition behavior of conspecific gravid $A n$. gambiae females, causing a positive response to cues from first instars and a negative response to cues from fourth instars.

A number of compounds have been shown to attract Anopheles mosquitoes to oviposition sites. Recently, Lindh et al. (2015) identified the sesquiterpene alcohol cedrol as an oviposition attractant of An. gambiae s.s.. The volatiles of grass species Echinochloa pyramidalis and E. stagnina were attractive to gravid females of An. coluzzii Wilkerson \& Coetzee and An. arabiensis Patton (Asmare et al. 2017); gravid females of An. arabiensis were furthermore attracted to volatiles from maize pollen, including alpha-pinene, limonene, $p$-cymene, nonanal and benzaldehyde (Wondwosen et al. 2017). Paradoxically, the compounds dimethyl disulphide (DMDS) and trimethyl disulphide (DMTS), products of decaying plant material, were identified as oviposition repellents for An. coluzzii (Suh et al. 2016). Additionally, Bermuda grass hay infusions contained olfactory compounds that repelled An. gambiae (Eneh et al. 2016a). These studies show that the oviposition behavior of An. gambiae s.l. females is affected by olfactory cues, which may be attractive or repellent, but the nature of these compounds is still poorly understood, especially concerning the interactions between water-associated cues and conspecific cues. While these studies have identified several compounds originating from natural breeding sites affecting oviposition, compounds associated with larvae have to-date not been described.

The identification of infochemicals influencing oviposition behavior is important for a better understanding of the chemical ecology of oviposition, manipulation of mosquito oviposition behavior and application in monitoring and control methods (Munga et al. 2006; Sumba et al. 2004; Sumba et al. 2008). The identification of oviposition attractant chemicals is expected to complement the current methods of monitoring and controlling mosquito populations (Dugassa et al. 2016; Perich et al. 2003; Ponnusamy et al. 2015). The present study was carried out to determine the effect of larval stage on attraction and repellence of gravid females of $A n$. gambiae in laboratory and semi-field settings and to identify volatile chemicals produced by larvae of this species that mediate this behavior.

\section{Methods and Materials}

Laboratory experiments were conducted at the Laboratory of Entomology of Wageningen University \& Research in The Netherlands and at the Amani Research Centre of the National Institute for Medical Research, Muheza, Tanzania. The semi-field study was conducted at the Amani Research Centre in Tanzania.

Insects and Rearing Procedures We used Anopheles coluzzii originating from Suakoko, Liberia, previously known as $A n$. gambiae s.s. M form (Coetzee et al. 2013) that was reared at the Laboratory of Entomology, Wageningen University \& Research, The Netherlands. Larvae were raised under standardized conditions (water surface $>2 \mathrm{~cm}^{2}$ per larva), in a climate-controlled chamber at $28{ }^{\circ} \mathrm{C}$ and $80 \%$ relative humidity, with a 12:12 h L:D photoperiod. Larvae were reared in 2.51 plastic trays filled with acclimatized tap water and were fed $0.003 \mathrm{~g} /$ larva Tetramin ${ }^{\circledR}$ fish food (Tetra Werke, Germany per day). Pupae were collected daily and placed in small cups inside a $30 \times 30 \times 30 \mathrm{~cm}$ Bugdorm ${ }^{\circledR}$ cage (https://www.shop. bugdorm.com) for emergence. Adults (males and females) were kept in a Bugdorm ${ }^{\circledR}$ cage with ad libitum access to a $6 \%$ glucose solution. When 3-5 days old, females were fed blood by offering a human arm. Gravid mosquitoes from this group were used to study response to volatiles produced by larvae in the laboratory. Ethical approval for blood feeding was not requested as this method of blood feeding is not subject to the Dutch Act of Medical Research involving Human Subjects (WMO). In our anopheline mosquito cultures, no experimental infections took place and mosquitoes were free of any parasite.

At the Amani Research Centre, adult An. gambiae s.s. (originating from Ifakara, southern-central Tanzania) were kept in a $30 \times 30 \times 30 \mathrm{~cm}$ metal framed cage covered with netting. Larvae were reared in round aluminium pans with a diameter of $27 \mathrm{~cm}$, filled with filtered tap water to a depth of $2 \mathrm{~cm}$. Larvae were fed on Tetramin $®$ fish food (Tetra Werke, Germany) and were kept in a 12:12 h L:D light regime. The temperature in the insectarium was $29{ }^{\circ} \mathrm{C}$. Pupae were removed from the trays daily and were placed in the mosquito cages for emergence. Male and female mosquitoes were kept 
in the same cages. For blood feeding, 3-5 days old females were offered a human arm. An approval involving human subjects in blood feeding mosquitoes was obtained from the Medical Research Coordinating Committee of the National Institute for Medical Research in Tanzania. The same volunteer donated blood to all batches of mosquitoes throughout the study, and mosquitoes were fed blood only once during their lifetime. Gravid mosquitoes from this group were used to study the response to infochemicals in the laboratory and semi-field experiments.

Oviposition in Response to Larvae Experiments concerning the oviposition behavior in response to the presence of first or fourth instars were performed at the Laboratory of Entomology in Wageningen. The aim of this experiment was to investigate if the concept that larval habitats of An. coluzzii emit chemical cues that mediate oviposition behavior in conspecific adults. Nine-day old female An. coluzzii were fed blood on a human arm for ten minutes, two days before the start of the experiment and were kept as described above.

Early-stage larvae (L1) were collected two days after oviposition using a glass pipette. Water drops with larvae were placed on the bottom of a white, dry rearing tray and larvae were counted. Late-stage larval instars (L3/L4) were collected with a plastic pipette $(5 \mathrm{ml})$ and were counted in a similar way as L1 larvae. A total of 100 larvae of the same developmental stage were placed in a plastic oviposition cup $(5.25 \mathrm{~cm}$ diameter $\times 3 \mathrm{~cm}$ height). The volume of rearing water was removed to a minimum before the transfer of larvae and after the transfer of the larvae cups were filled with tap water to a volume of $30 \mathrm{ml}$.

Wet filter paper, $125 \mathrm{~mm}$ in diameter, Whatman ${ }^{\circledR}$ (Whatman International Ltd., Maidstone, England) was placed over the cup, serving as an oviposition site for the mosquitoes thus preventing stimulation by visual stimuli. To prevent drying out of the oviposition paper, a cylinder made of filter paper was placed in the cups (Fig. 1, left panel). This cylinder ensured that when the water level in the cup decreased, the oviposition paper remained wet. Moreover, because of the cylinder, the oviposition paper did not have to be in contact with the liquid, which would decrease the area of the water surface for the larvae to breathe. Larvae were placed within and outside of the cylinder. As a control the cups were filled with $30 \mathrm{ml}$ tap water.

Gravid mosquitoes were held solitary in a $30 \times 30 \times$ $30 \mathrm{~cm}$ Bugdorm ${ }^{\circledR}$ cage for $48 \mathrm{~h}$ - two oviposition periods (Fritz et al. 2008), under the circumstances described above. Each mosquito was given a choice between ovipositing in a treated cup, with either 100 early-stage larvae (L1) or 100 late-stage larvae (L4), and a control cup. Cups were placed diagonally in corners as far from each other as possible, at a distance of approximately $30 \mathrm{~cm}$. Eggs were counted after 24 and $48 \mathrm{~h}$ and the total number of eggs after $48 \mathrm{~h}$ was taken as the response of the mosquitoes. Each treatment was repeated 17 times.

Collection and Identification of Chemicals Three procedures were conducted at the Laboratory of Entomology, Wageningen University \& Research: (i) a proof of concept for emission of volatile chemicals from larval habitats, (ii) collection of volatile chemicals from larval habitats by headspace techniques and (iii) identification of entrapped chemicals by GC-MS.

Volatile compounds released by water containing either no larvae, early stage or late stage larvae of An. coluzzii were collected from cups filled with $30 \mathrm{ml}$ of tap water placed in separate air-tight cuvettes.

Volatiles were collected using the "purge and trap" approach on an adsorbing polymer: Tenax-TA 20/35 (Alltech, USA). To reduce background volatiles, air was sucked into the cuvette through a carbon filter and a cartridge containing $100 \mathrm{mg}$ Tenax-TA. Headspace volatiles were trapped at a flow rate of $100 \mathrm{ml} / \mathrm{min}$ for $24 \mathrm{~h}$ on a second cartridge containing $100 \mathrm{mg}$ Tenax TA connected to the outlet of the cuvette. Samples were released from the adsorbent using a thermodesorption unit (Ultra 50:50 TD, Markes, Llantrisant, UK) while re-collected in an electrically cooled cold trap (Unity, Markes) and followed by gas chromatography (Trace
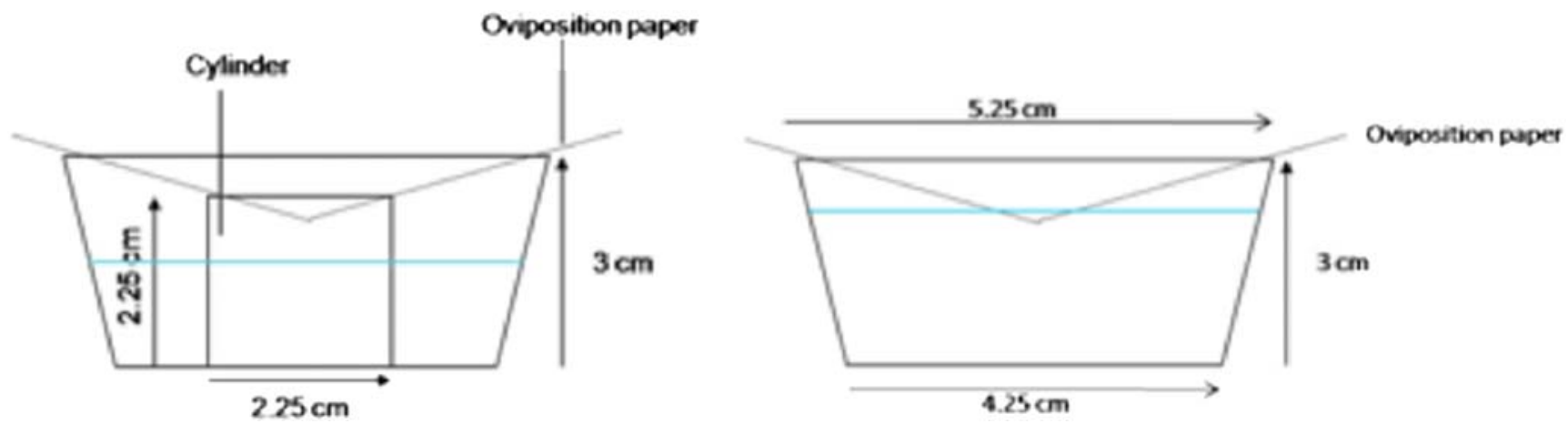

Fig. 1 Schematic representation of oviposition cups used in oviposition experiments; showing the set up with larvae (left) and chemicals (right) 
GC Ultra) and mass spectrometry (Trace DSQ quadrupole mass spectrometer), both from Thermo (Thermo Fisher Scientific, Waltham, USA).

The program for thermal desorption consisted of dry purging for $3 \mathrm{~min}$ and pre-purging for $1 \mathrm{~min}$ using helium (residual oxygen removal) at $30^{\circ} \mathrm{C}$. This was followed by tube desorption at $250{ }^{\circ} \mathrm{C}$ for $3 \mathrm{~min}$ and the volatiles were focused on a cold trap at $0{ }^{\circ} \mathrm{C}$. Injection onto the analytical column was achieved by heating of the cold trap at the maximum heating acceleration $\left(>60{ }^{\circ} \mathrm{C}\right.$ per second $)$ to $250{ }^{\circ} \mathrm{C}$ in a split mode at a split ratio of 1:6. The transfer line between the cold trap and the $\mathrm{GC}$ was kept at $160{ }^{\circ} \mathrm{C}$ throughout the analysis.

A $30 \mathrm{~m} \times 0.25 \mathrm{~mm}$ ID $\times 1.0 \mu \mathrm{m}$ F.T. capillary GC column (Rtx-5 MS, Restek, USA) with helium (5.0 grade) as carrier gas at a flow rate of $1.0 \mathrm{~mL} / \mathrm{min}$ was used for separation of volatile compounds. The GC temperature was programmed as follows: $45^{\circ} \mathrm{C}$ for $3 \mathrm{~min}$, followed by a ramp of $8{ }^{\circ} \mathrm{C} / \mathrm{min}$ to $280{ }^{\circ} \mathrm{C}$ and was held at $280{ }^{\circ} \mathrm{C}$ for $2 \mathrm{~min}$. The transfer line between the GC and MS was set to $275^{\circ} \mathrm{C}$. MS spectra were recorded by ionization of the column effluent by electron impact (EI) ionization at $70 \mathrm{eV}$, scanning in positive mode from 35 to $300 \mathrm{~m} / \mathrm{z}$ with a speed of 5 scans per second. The ion source temperature was set to $250{ }^{\circ} \mathrm{C}$ and the filament was switched off from 13.6-13.8 min because of a high background peak. Peak identification was performed by comparing the obtained spectra with those in the NIST library (version $2.0 \mathrm{~d}$ ), experimentally calculated retention indices and using the retention times of authentic synthetic reference compounds.

Chemicals The synthetic chemicals dimethyl disulfide (DMDS, $\geq 99.0 \%$ ), dimethyl trisulfide (DMTS, $\geq 98.0 \%$ ), nonane $(\geq 99.0 \%)$ and 2,4-pentanedione (2,4-PD), which is also known as acetylacetone (ReagentPlus ${ }^{\circledR}, \geq 99.0 \%$ ), all from Sigma Aldrich (Sigma Aldrich, Chemie BV, Zwijndrecht, The Netherlands), were used for testing the oviposition response. Since all of these chemicals were insoluble in water, they were dissolved in methanol and Tween20, in the following ratios: $55 \mathrm{~g}$ (test chemical) $+40 \mathrm{ml}$ Methanol $+5 \mathrm{ml}$ Tween20. Hereafter, the chemicals were dissolved and diluted in distilled water to make 11 of diluted chemicals and dilution process continued until the required concentrations for bioassay was reached. The final concentrations of all chemicals ranged from $10^{-7}$ to $10^{-12} \mathrm{M}$.

Oviposition Bioassays Identified chemicals were tested for effects on oviposition behavior at the Amani Research Centre, Muheza, Tanzania, using An. gambiae s.s mosquitoes (Ifakara strain). Two experiments were conducted: laboratory experiments were performed under the same conditions and with the same materials as was done in
Wageningen, with the aim to select and confirm effective doses for each chemical. Semi-field experiments were designed to verify potential attractive/repellent effects of these compounds under natural ambient conditions.

Dose Response Effects on Oviposition DMDS, DMTS, 2,4-PD and nonane were each tested at six different doses in a four cups choice set up against controls. Gravid An. gambiae s.s (48 h post blood feeding) were placed in a $30 \times 30 \times 30 \mathrm{~cm}$ cage. In each cage cups containing $30 \mathrm{ml}$ of a solution of the chemical in concentrations of $10^{-7} \mathrm{M}, 10^{-8} \mathrm{M}, 10^{-9} \mathrm{M}$ and control, or in concentrations of $10^{-10} \mathrm{M}, 10^{-11} \mathrm{M}, 10^{-12} \mathrm{M}$ and control were placed. Each of the four oviposition cups was placed in a corner of the cage. Mosquitoes were given a $6 \%$ glucose solution as an additional food source. The determination of the most effective concentration was based on the total number and percentage of eggs found in both control and treated cups after $36 \mathrm{~h}$ (two nights).

Dual Choice Experiments with Selected Doses Based on the results from the dose-response test, dual choice experiments were performed with single compounds. The following concentrations of single compounds were tested against respective controls:

(a) DMDS: $10^{-7} \mathrm{M}$ and $10^{-9} \mathrm{M}$

(b) DMTS: $10^{-9} \mathrm{M}$ and $10^{-11} \mathrm{M}$

(c) 2,4-PD: $10^{-10} \mathrm{M}$

(d) nonane: $10^{-11} \mathrm{M}$

Determination of Oviposition Activity and Egg Retention To ascertain the effect of emitted infochemicals as either attractive or repellent, an oviposition activity index (OAI) was calculated using the formula $\mathrm{OAI}=(\mathrm{Nt}-\mathrm{Nc}) /(\mathrm{Nt}+\mathrm{Nc})($ Kramer and Mulla 1979), with $\mathrm{Nt}=$ number of eggs laid in the egg cup with larvae or test compound, and $\mathrm{Nc}=$ number of eggs oviposited in the cup with control materials. Individual gravid Anopheles coluzzii females were exposed to emanations of either 100 first or 100 fourth instars; individual gravid females of An. gambiae s.s. were exposed to nonane $\left(10^{-11} \mathrm{M}\right), 2,4-$ DP $\left(10^{-10} \mathrm{M}\right)$, DMDS $\left(10^{-7} \mathrm{M}\right)$ or DMTS $\left(10^{-9} \mathrm{M}\right)$, respectively. Each treatment was replicated 17 times.

At the end of the dual-choice experiments in the laboratory, females were killed and the status of their ovaries was examined for egg retention by dissection of the ovaries. The abdomen of the female was placed on a glass slide, opened with fine surgical forceps and the ovaries were gently pulled out and placed in a drop of physiological saline. The ovaries were examined at 400x magnification under a dissecting microscope. The number of mature eggs present per female were counted (Takken et al. 2013). 
Semi-Field Oviposition Experiments The effects of DMTS at a concentration of $10^{-11} \mathrm{M}$, DMDS at $10^{-7} \mathrm{M}$, nonane at $10^{-11} \mathrm{M}$ and 2,4-PD at $10^{-10} \mathrm{M}$ on oviposition response were investigated against their controls (distilled water+methanol+ Tween20) in a dual choice assay in a semi-field situation (mosquito spheres) at Muheza in Tanzania, under natural ambient conditions (Knols et al. 2002). The objective was to scale up the exploration into a field situation and compare laboratory with semi-field results. Three mosquito spheres $(11.4 \times 7.1 \times 5.0 \mathrm{~m})$ were used in this study (Fig. 2). During the experimental period, the average temperatures in the spheres ranged from a minimum of $16{ }^{\circ} \mathrm{C}$ during the night to a maximum of $32{ }^{\circ} \mathrm{C}$ during the day. The average relative humidity $(\mathrm{RH})$ ranged from a minimum of $40 \%$ to a maximum of $100 \%$.

Two symmetrical holes were dug in the ground at the centre of each sphere, and were located $3 \mathrm{~m}$ apart. A green plastic bowl (diameter $26 \mathrm{~cm}$, height $10 \mathrm{~cm}$ ) was placed in each hole as an artificial breeding site. The bowls were placed in such a way that the rim of the bowls was at ground level. The bowls had a capacity of 51 and were filled with 31 of the test solutions of the concentrations mentioned above or with distilled water.

A total of 240 mosquitoes (An. gambiae s.s.) were given an opportunity to blood feed twice, on day 3 and day 4 after emergence, and were released on day 5, when eggs had matured (Takken et al. 1998). Mosquitoes were released one hour before dusk (at about 18:00 h), from the centre of the sphere between the bowls. Eggs were counted on the first and second morning after releasing mosquitoes and the solutions were replaced after every experiment. The total number of eggs after two nights was taken as the oviposition response. Each pair in this experiment was replicated 17 times.

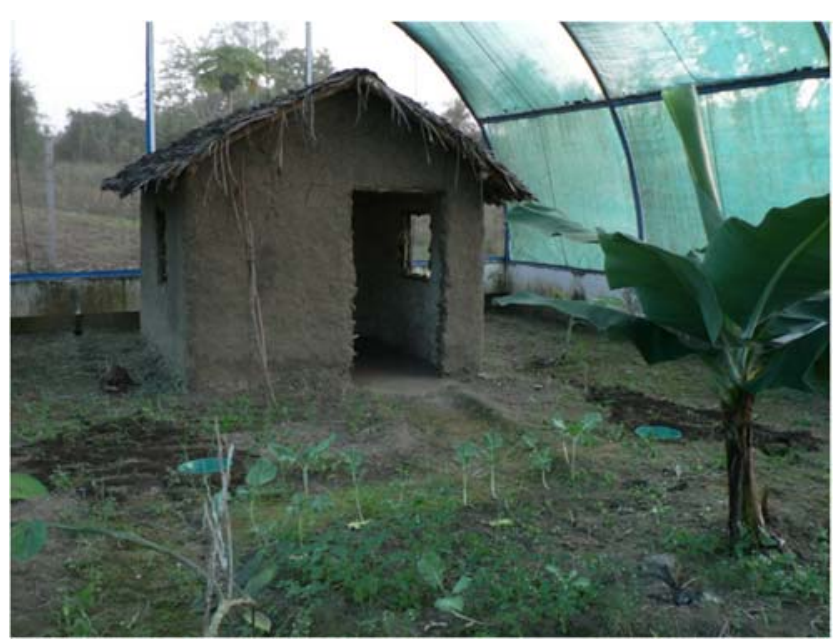

Fig. 2 Mosquito sphere at Muheza in which semi-field oviposition studies took place. The sphere had a small house, banana plants, ground vegetation and 2 oviposition bowls in front of the house
Data Analysis Differences in oviposition preferences of mosquitoes were analysed using the Wilcoxon matched-pairs signed rank test and Mann-Whitney test for matched-pairs. This non-parametric test was used because the data were not normally distributed. To compare more than two paired groups, like with the dose response test, the Friedman test was used.

Analysis of OAI data was done by comparing the response value with zero. When the OAI values differed significantly from zero with positive or negative values, the treatment was considered to have significant attractant or repellent effect, respectively, on oviposition behavior of gravid females. Oviposition preference of gravid females was determined by OAI values using the Wilcoxon signed rank test $(\alpha=0.05$, two-sided). The OAI was also used to compare behavioral assays involving larvae and chemical assays involving identified infochemicals.

The amount of volatiles quantified in headspace collections was analysed using the Kruskal-Wallis test. Differences in egg retention were analysed using the Mann-Whitney U-test.

All tests were performed in SPSS, version 20 (IBM, Armonk, NY, USA).

Ethical Clearance The study was conducted according to Standard Operating Procedures approved by the Medical Research Coordinating Committee (MRCC) of the National Institute for Medical Research (NIMR), Tanzania. It received a research permit from MRCC with reference number NIMR/HQ/R.8a/Vol. IX/573 and a permit from the Tanzania Commission for Science and Technology with reference number CST/RCA 138/225/2008. In the Netherlands, ethical approval for blood feeding was not requested as this method of blood feeding is not subject to the Dutch Act of Medical Research involving Human Subjects (WMO).

\section{Results}

Oviposition in Response to Larvae of Different Development Stages Significantly more eggs were deposited in cups containing L1 larvae than in control cups $(P<0.0001$, Wilcoxon signed rank test), with a median $( \pm \mathrm{SE})$ of $31.0 \pm 2.2$ over 0 in control, respectively (Fig. 3). When given a choice between 100 L4 larvae and a control, mosquitoes deposited more eggs in the control cups $(P<0.0001$, Wilcoxon signed rank test), i.e. median of 0 in the cups with L4 larvae compared to $32.0 \pm$ 3.0 in the control cups (Fig. 3). When two cups with water were tested, there was no difference in the median number of eggs per cup (17.0 \pm 3.6 and $19.0 \pm 3.8$ eggs, respectively).

Collection and Identification of Infochemicals Analysis of the headspace extract from water containing larvae by GCMS showed that four out of sixteen volatile compounds 
Fig. 3 Median number of eggs laid by An. gambiae s.s. in a dualchoice test with first and fourth instars. i) cup containing 100 first instars against a control cup, ii) a cup containing 100 fourth instars against a control cup, iii) two cups containing distilled water. Asterisks indicates significance between treatment and control (***, $P<0.001$, Wilcoxon signed rank test)

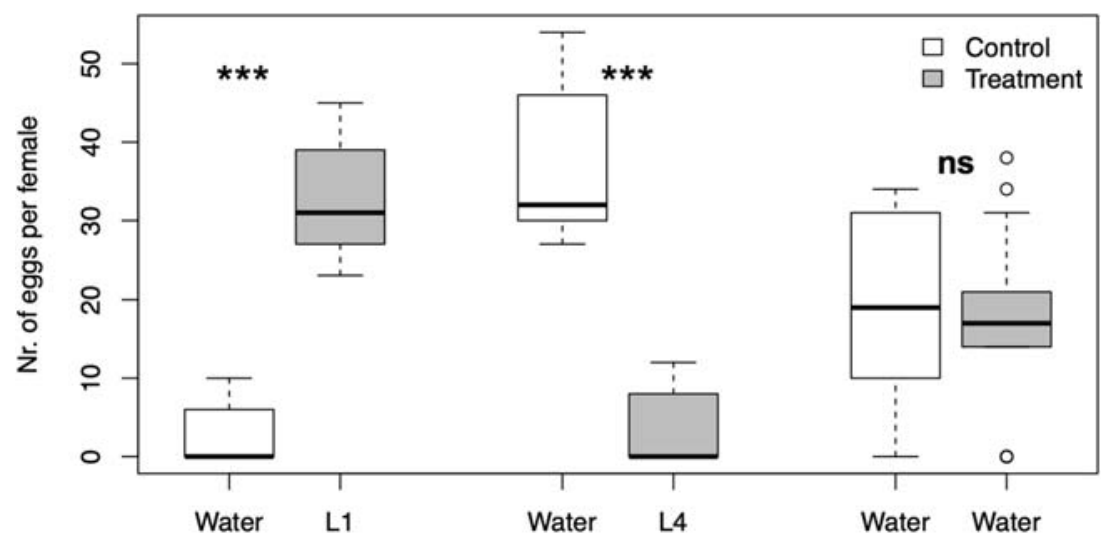

that showed a difference between control, early stage larvae and late stage larvae were found (Fig. 4). The compounds were identified by matches with database spectra, and by matching their retention times and mass spectra to standards of synthetic compounds. After analysis, only two of these compounds were significantly different in abundance between the treatments. Dimethyl disulfide (DMDS; $P=0.021$, Kruskal Wallis, $n=5$ ) and dimethyl trisulfide (DMTS; $P=0.006$, Kruskal Wallis, $\mathrm{n}=5$ ) were collected in higher amounts from cups containing latestage larvae than from the control cups or cups containing early-stage larvae (Fig. 5a, b). Nonane $(P=0.275$, Kruskal Wallis, $\mathrm{n}=5)$ and 2,4-PD $(P=0.081$, Kruskal Wallis, $\mathrm{n}=5$ ) were equally abundant in the headspace from early-stage and late-stage larvae but differed from the control $(P<0.05)$. There was no significant difference in abundance of nonane and 2,4-PD between the cups containing early-stage and late-stage larvae (Fig. 5c, d).

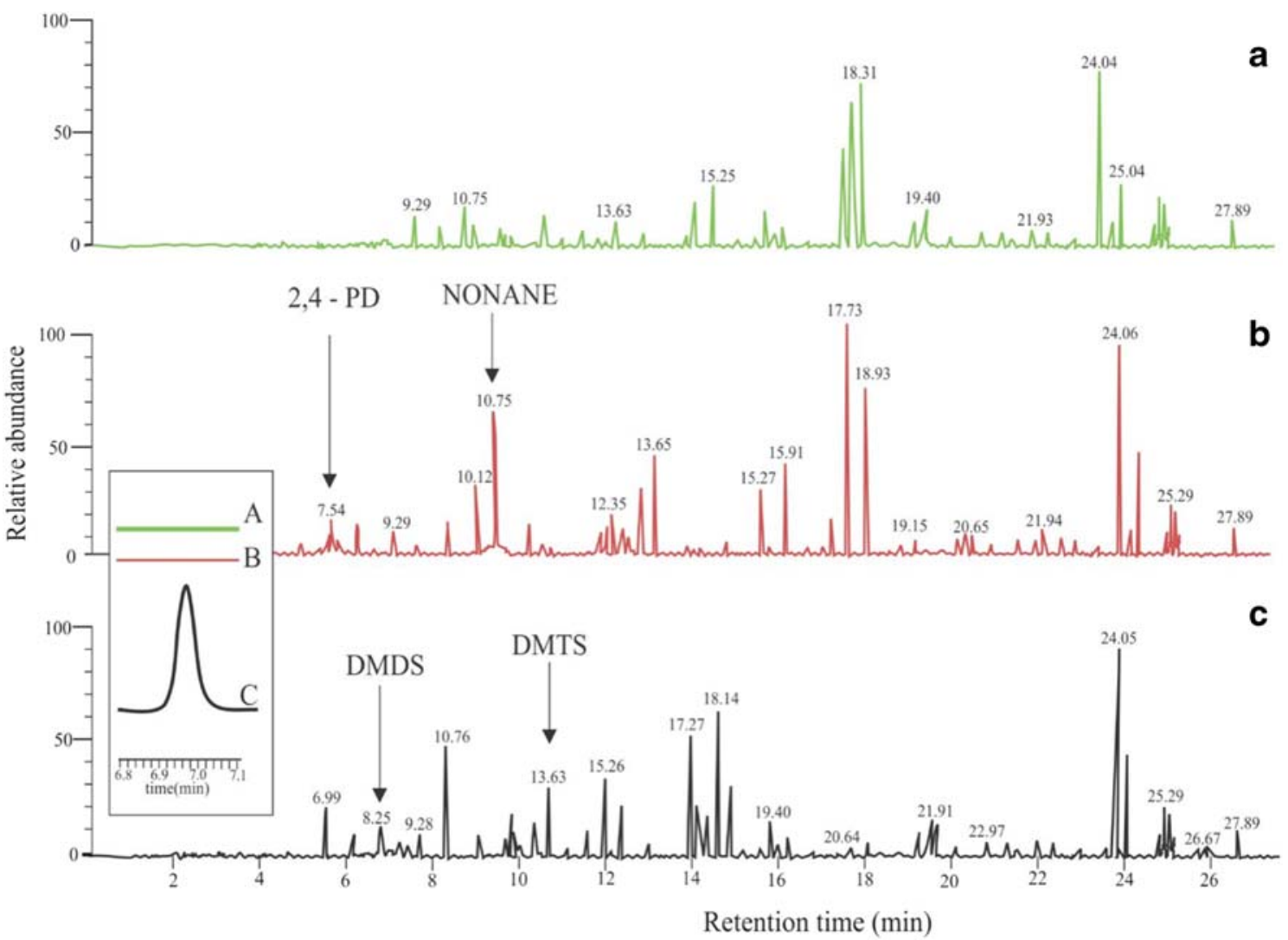

Fig. 4 Partial chromatograms for headspace from water containing larvae and control. Volatile samples were entrapped from control water (a) and water with either of two different larval stages, i.e. early stage (L1) (b) and late stage (L4) (c). A mass range zoom $(\mathrm{m} / \mathrm{z}=94)$ representing DMDS is added. Y-axis represents equal relative abundances of the different analyses, normalized for the most abundant TIC signal. Peaks for 2,4pentanedione, nonane, dimethyl disulfide and dimethyl trisulfide are labeled 
Fig. 5 Relative abundance of the selected chemicals in control cups, cups with early stage (L1) and cups with late stage larvae (L4). Graphs show mean abundances of DMDS (a), DMTS (b), nonane (c) and 2,4-PD. Asterisks indicate significant RA value different from control (*, $P<0.05$, **, $\mathrm{P}<0.1$, Kruskal Wallis, $N=5$ )

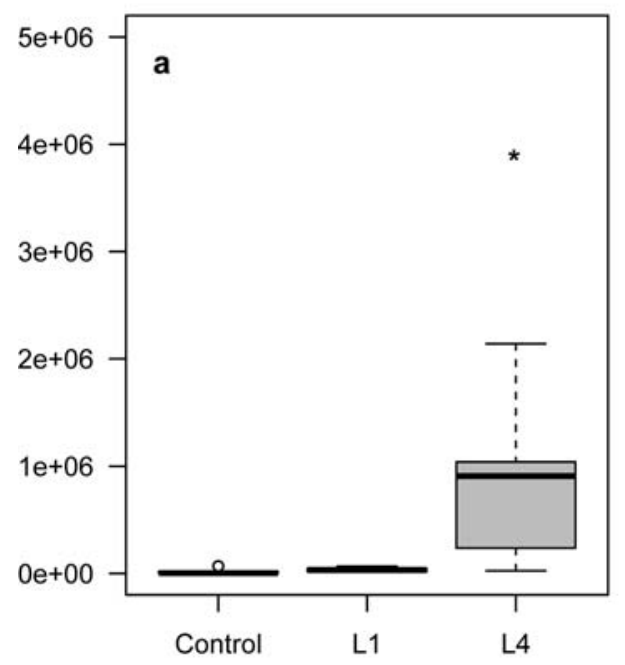

Nonane

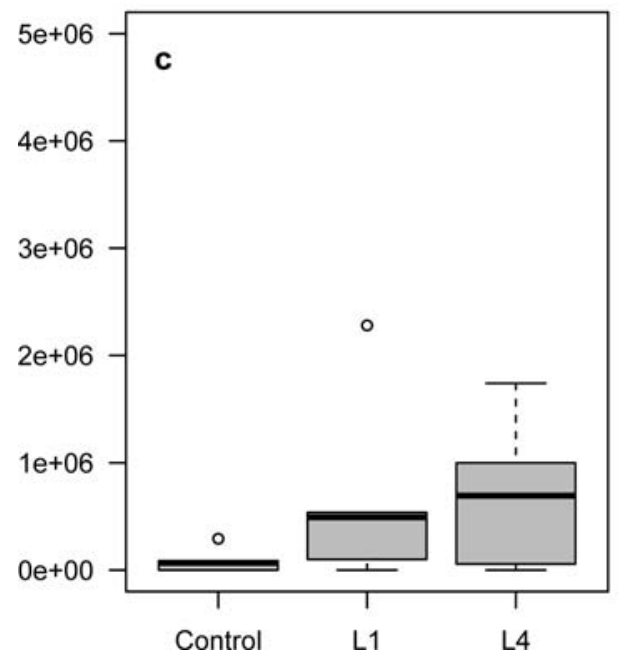

Dimethyl trisulfide

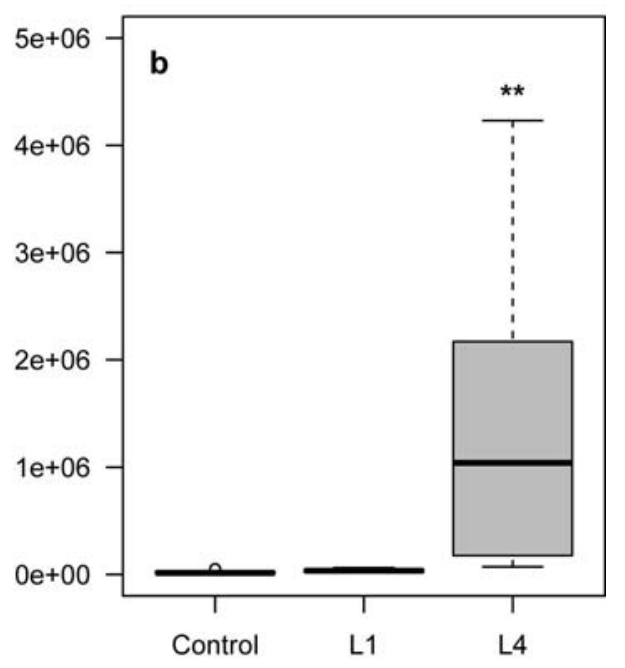

2,4-Pentanedione

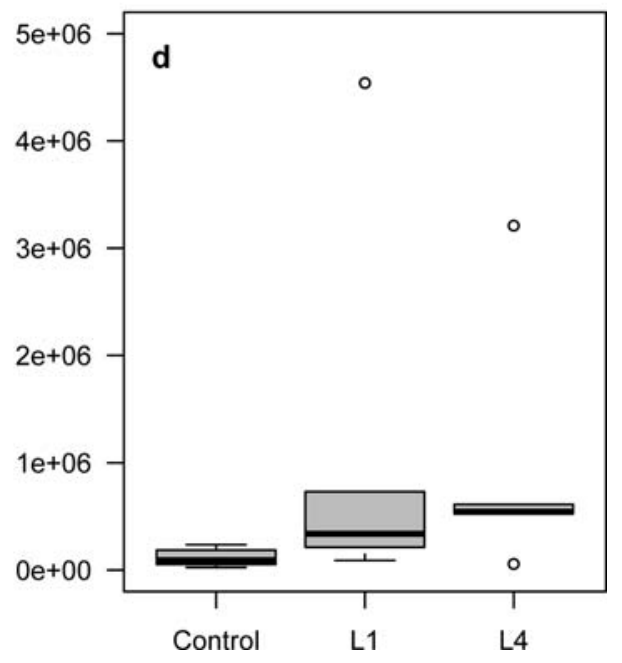

These four compounds were selected as putative chemicals influencing oviposition because of their marked greater abundance compared to control.

Dose Response Effects No significant differences were found in the number of eggs between the different concentrations and control $\left(P>0.05\right.$, Friedman test, $\mathrm{N}_{\text {[all chemicals tested] }}=$ 12). The concentration of DMDS that received fewest eggs was $5.5 \times 10^{-7} \mathrm{M}$ with an Oviposition Activity Index $(\mathrm{OAI})=$ -0.78 , average percentage \pm SE of $6.5 \pm 6.46 \%$ of the total number of eggs oviposited and was selected as concentration used in the follow-up experiments. In the second set of concentrations of DMTS (ranging from $5.5 \times 10^{-10}-5.5 \times$ $10^{-12} \mathrm{M}$ ) mosquitoes in two of the three cages did not oviposit at all. At the concentration $5.5 \times 10^{-11} \mathrm{M}$, oviposition bowls received fewest eggs with an OAI equal to -0.17 , and this concentration was used for further experiments (Fig. S1).

Differences in oviposition response between the tested concentrations of nonane were small for both ranges and the concentration of. $5.5 \times 10^{-11} \mathrm{M}$ with an average percentage of 38.9, mean $72.7 \pm 40.3$, OAI $=+0.21$ was selected for further study. When testing 2,4-PD, the concentration of $5.5 \times$ $10^{-10} \mathrm{M}$ received most eggs, with an average percentage of 47.4 , mean $52.3 \pm 28.3$ and OAI of +0.42 . These concentrations were selected for further experiments.

Dual Choice Experiments in the Laboratory with Selected Chemicals In the laboratory in Muheza, differences in 
Table 1 Results of oviposition response and examination for egg retention of female An. gambiae s.s. exposed to selected concentrations of DMDS, DMTS, nonane and 2,4-pentanedione in a dual-choice set up against distilled water

\begin{tabular}{|c|c|c|c|c|c|c|c|}
\hline \multirow[t]{2}{*}{ Treatment } & \multirow[t]{2}{*}{ Dose } & \multirow[t]{2}{*}{$\mathrm{N}$} & \multicolumn{3}{|c|}{ Mean no. \pm SE of eggs per female } & \multirow[t]{2}{*}{$\%$ females that oviposited } & \multirow[t]{2}{*}{ Mean no. \pm SE retained eggs per female** } \\
\hline & & & Treatment & Control & $\mathrm{P}^{*}$ & & \\
\hline DMDS & $5.5^{*} 10^{-7}$ & 17 & $13.41 \pm 5.66$ & $18.12 \pm 7.51$ & 0.647 & 47 & $52.06 \pm 14.43 \mathrm{~b}$ \\
\hline DMTS & $5.5^{*} 10^{-11}$ & 16 & $4.69 \pm 2.48$ & $8.88 \pm 5.45$ & 0.799 & 44 & $37.13 \pm 9.02 b$ \\
\hline Nonane & $5.5^{*} 10^{-11}$ & 17 & $24.00 \pm 10.27$ & $47.29 \pm 11.29$ & 0.147 & 88 & $15.90 \pm 10.95 \mathrm{a}$ \\
\hline 2,4-Pentanedione & $5.5 * 10^{-10}$ & 14 & $32.86 \pm 10.32$ & $36.43 \pm 9.47$ & 0.861 & 100 & $6.92 \pm 6.92 \mathrm{a}$ \\
\hline Water (=control) & & 10 & $48.30 \pm 15.59$ & $19.90 \pm 9.62$ & 0.241 & 100 & $2.20 \pm 2.20 \mathrm{a}$ \\
\hline
\end{tabular}

$\mathrm{N}=$ number of replicates with one female per dual-choice test

*Wilcoxon signed rank test

**Differences in letters behind each value indicate a significant difference between the mean number of of retained eggs per female $(P=0.018$ for DMDS and $P=0.007$ for DMTS, Mann-Whitney U-test)

number of eggs laid between treated and control cups were not significant for any treatment (Table 1 , Wilcoxon signed rank test). Only $47 \%$ and $44 \%$ of the mosquitoes exposed to DMDS and DMTS, respectively, developed eggs and oviposited compared to $100 \%$ in the control. The remaining mosquitoes of the DMDS and DMTS treatments had fully developed eggs, but did not oviposit. As a result, the number of eggs that were retained by mosquitoes exposed to the methylsulfides were significantly higher than of mosquitoes in cages with water only $(P=0.018$ for DMDS and $P=0.007$ for DMTS, Mann-Whitney U). For nonane, 2,4-PD and the control experiments, the percentages of mosquitoes that oviposited were $100 \%, 88 \%$ and $100 \%$, respectively. The number of eggs retained by mosquitoes exposed to nonane and 2,4-PD were not different from the control.
Semi-Field Experiment There were marked differences in the oviposition effects of DMTS and DMDS on the one hand, and nonane and 2,4-PD on the other hand (Fig. 6). Bowls treated with DMDS or DMTS received significantly fewer eggs than the controls (for DMDS: $P<0.0001, n=17$, Median $[$ DMDS] $=$ 154; Median ${ }_{\text {[control] }}=341$; for DMTS: $P=0.049, \mathrm{n}=17$, Median $_{[\mathrm{DMTS}]}=35$; Median $_{[\mathrm{control}]}=353$. The bowl treated with nonane received significantly more eggs than the respective controls $\left(P<0.0001, \mathrm{n}=17\right.$, Median $_{[\text {nonane] }}=958$; Median $_{[\text {control] }}=384$. Likewise, the bowl treated with 2,4$\mathrm{PD}$ received significantly more eggs than the respective controls $(P<0.001, \mathrm{n}=17$, Median $[2,4-\mathrm{PD}]=726$; Median $[$ control $]=406$. The oviposition response to control treatments was similar between the different experiments, indicating consistence in results between different experiments (Fig. 6). The OAIs for nonane and 2,4-PD were positive, indicating
Fig. 6 Oviposition response of Anopheles gambiae, expressed as the median number of eggs laid per female, when tested in a dualchoice essay with dimethyl disulfate (DMDS), dimethyl trisulfate (DMTS), nonane or 2,4pentanedione against distilled water. Asterisks indicate significant differences in number of eggs in treatment versus control $(*, \mathrm{P}<0.05$, **, $\mathrm{P}<$ 0.001 , ***, $P<0.0001$; Wilcoxon signed rank test)

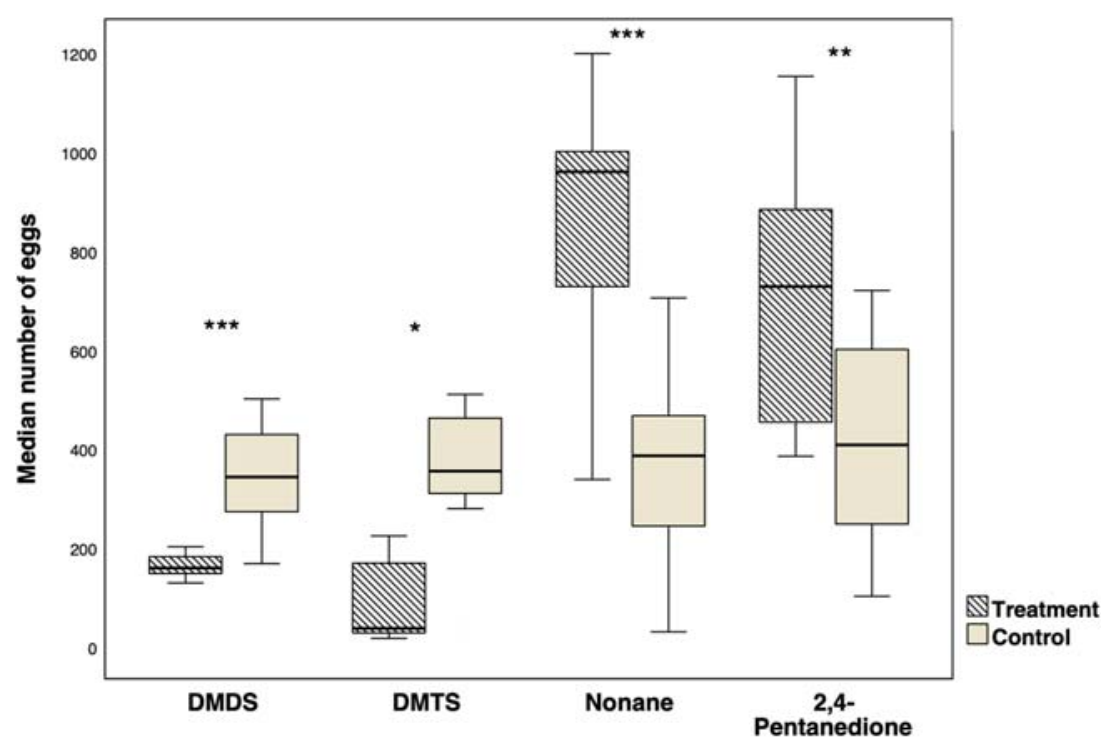

Chemical compound 
Fig. 7 Oviposition activity index (OAI) of gravid Anopheles coluzzii exposed to first and fourth instars, and gravid Anopheles gambiae s.s. exposed to nonane, 2,4-pentanedione, dimethyl disulfate or dimethyl trisulfate tested in a dual-choice assay. Asterisks indicate an OAI value significantly different from zero $(* *, \mathrm{P}<0.001$, ***, $\mathrm{P}<$ 0.0001 ; Wilcoxon signed rank test)

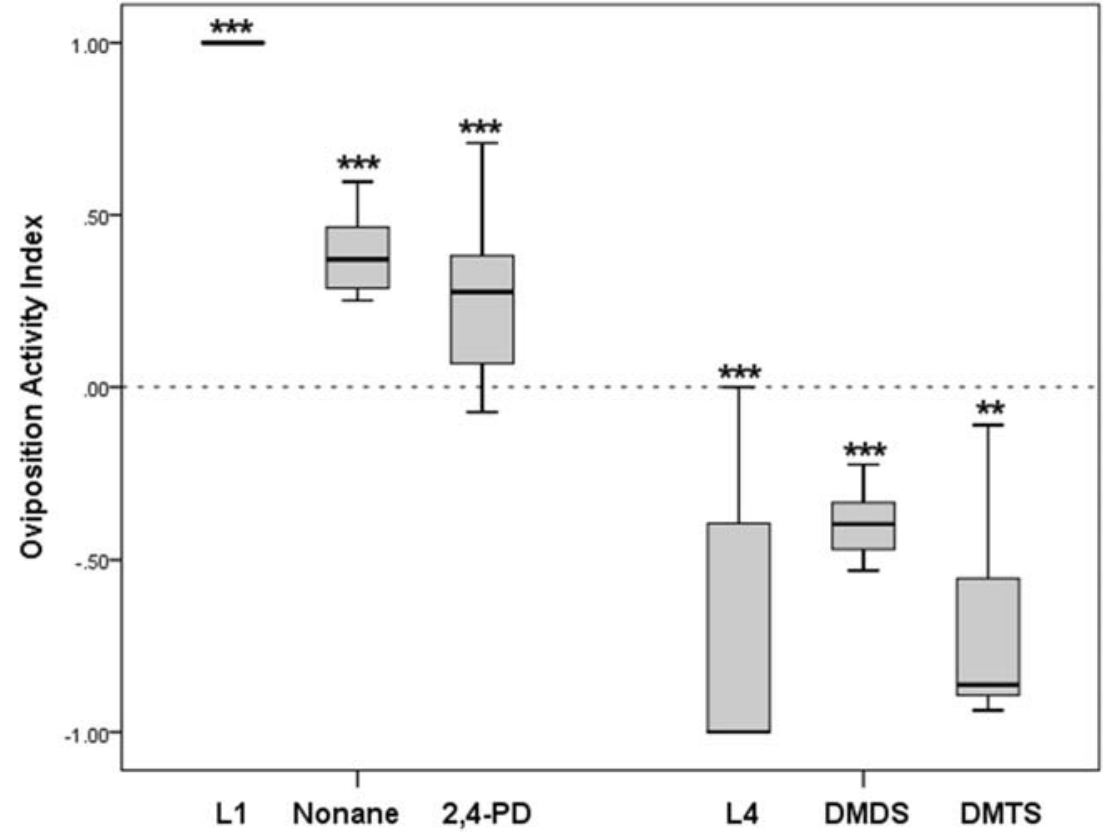

stimulation of oviposition activity whereas those for DMDS and DMTS were negative, indicating inhibition of oviposition activity in the presence of these infochemicals.

\section{Oviposition Activity with Live Larvae and Selected Chemicals}

The oviposition activity in the presence of early and late stage larvae was compared to oviposition activity in the presence of infochemicals entrapped from early and late stage larvae. The oviposition activities of mosquitoes followed a similar trend in response to $\mathrm{L} 1$, nonane and 2,4 PD with a positive value that indicates stimulation of oviposition activities (Fig. 7). The median oviposition activity was highest with $\mathrm{L} 1$ (OAI = $1.00 \pm 0.06, \mathrm{n}=17, P<0.0001)$ followed by nonane $(\mathrm{OAI}=$ $0.36 \pm 0.09, \mathrm{n}=17, P<0.0001)$ and then $2,4-\mathrm{PD}(\mathrm{OAI}=0.28$ $\pm 0.07, \mathrm{n}=17, P<0.001)$. Also, the oviposition activities in response to L4, DMDS and DMTS followed a similar trend, with a negative value suggesting inhibition of oviposition activities (Fig. 7). Fourth instars had the lowest OAI values, (median OAI $=-1.00 \pm 0.06, \mathrm{n}=17, P<0.0001$ ) followed by DMTS (median OAI $=-0.85 \pm 0.19, \mathrm{n}=17, P=0.0001$ ) and DMDS (median OAI $=-0.4 \pm 0.03, \mathrm{n}=17, P<0.0001$ ).

\section{Discussion}

Oviposition behavior of An. gambiae females is affected by volatile chemicals associated with conspecific larvae, where first instars affect oviposition positively, and fourth instars cause deterrence and even inhibition of oviposition. Nonane and 2,4-PD are putative attractants, and in a semi-field setting water bodies containing nonane or 2,4-PD received significantly more eggs than untreated water. DMDS and DMTS acted as oviposition repellents and caused egg retention. The data suggest that the oviposition response of these anophelines is mediated by infochemicals associated with conspecifics and that instar stage has a strong impact on this behavior.

Several studies have shown the role of breeding-site specific chemical volatiles affecting oviposition behavior of different members of the An. gambiae complex, apart from the role of water vapour as a general cue for all mosquito species (Okal et al. 2013). Indole has been identified to act as an attractant for An. gambiae, originating from larval water (Blackwell and Johnson 2000). Lindh et al. (2008) identified 13 putative oviposition attractants derived from bacteria in breeding water. More recently, cedrol was identified as an oviposition attractant for An. gambiae s.s. (Lindh et al. 2015). The compound was associated with water derived from a natural breeding site and shown to be the product of rhizomes of the grass Cyperus rotundus (Eneh et al. 2016b). This finding is in line with other studies which also showed a strong association of breeding site water, including infusions of plants growing in the water, and oviposition attraction of various members of the $A n$. gambiae complex (Herrera-Varela et al. 2014; Asmare et al. 2017). Other identified chemical cues mediating oviposition behavior in An. coluzzii mosquitoes include 2propylphenol and 4-methylcyclohexanol (Rinker et al. 2013). Recently, DMDS, DMTS and 6-methyl-5-hepten-2one (sulcatone) were identified from headspace analyses derived from habitats that repelled An. coluzzii (Suh et al. 2016) and were considered as putative oviposition repellents. This is corroborated by the findings of our study, where DMDS and DMTS caused a significant reduction in oviposition response. 
Insects have evolved a wide range of hydrocarbons to protect against dehydration, which had the potential to become signalling molecules involved in communication. Therefore, most insects produce straight chain n-alkanes (Gibbs 1998) which may serve as water-proofing agent, communication and signalling compound (Hölldobler and Wilson 2009). For a hydrocarbon to act as an infochemical from a distance, it must be volatile (Drijfhout et al. 2009), and nonane $\left(\mathrm{C}_{9} \mathrm{H}_{20}\right)$ fulfils this criterion. Across the range of environmental temperatures at which mosquitoes are active, nonane is a hydrocarbon which volatilizes easily, hence apt to convey information on suitability of a breeding site to gravid mosquitoes.

Behavioral effects of nonane and 2,4-PD on insects have not previously been reported to our knowledge. Recently, the attraction of gravid female An. arabiensis to sugarcane pollen was described and the mosquitoes expressed a positive response to headspace extracts of pollen. Among many headspace volatiles of sugarcane pollen, nonane was identified, but the compound did not elicit an EAG response in $A n$. arabiensis (Wondwosen 2016). Nonane has been described to show a slightly increased emission by glass beads contaminated with odors of a person less attractive to the yellow-fever mosquito Aedes aegypti (L.) than by a more attractive person. However, hydrocarbons generally contribute little to the overall attraction of host-seeking females of this species (Bernier et al. 2002) and a bioactive role of nonane in mosquito host seeking remained unconfirmed.

The OAI of the diketone 2,4-pentanedione is similar to the results obtained with various ketones studied earlier in different mosquito species (Knight and Corbet 1991). The ketones generally cause a positive ovipositional response (Ganesan et al. 2006). Moreover, the diketone 2,4-pentanedione is liable to keto-enol tautomerism, which is a process of migration of an atom within the same organic molecule, leading to a change in its structural skeleton, electron density distribution and chemical properties. 2,4-PD undergoes prototropic tautomerism and exists in equilibrium with its enol tautomer and differs just in the location of a double bond and a hydrogen atom (proton) which often migrates. Tautomers are the chameleons of chemistry, capable of changing by a simple change of phase from an apparent established structure to another and then back again when the original conditions are restored (Antonov 2013). Tautomers are interesting because their optical properties make them suitable as signalling molecules in sensors as they can rapidly switch between states. Many biologically important molecules have several tautomers, among which attractants which are used for luring insects (Pickett 1990). Our finding that in a semi-field setup nonane and 2,4PD elicited high oviposition activity suggests that both compounds may be used for mosquito surveillance and/or control, as odor baits in oviposition traps (Mboera et al. 2000b; Dugassa et al. 2016; Li et al. 2016).
In our study, both DMDS and DMTS had a negative effect on oviposition of An. gambiae s.s. and were collected only from the headspace of fourth larval instars, whereas nonane and 2,4-DP were found in the headspace of both first and fourth instars. Most mosquitoes did not oviposit when DMDS or DMTS were present in the cages, neither in the treated cup nor in the control cup. However, the possibility of saturation of air by these chemicals should not be ignored - as the size of the cage may have had an effect on this outcome. DMDS and DMTS are emitted by a broad range of natural sources; both are produced by bacteria (Khoga et al. 2002). DMDS can be found in human feces (Moore et al. 1987) and both compounds are known to be emitted by plants ( $\mathrm{Du}$ and Millar 1999; Stensmyr et al. 2002; Soler et al. 2007). Insecticidal and repelling properties of both DMDS and DMTS have been previously described. DMDS has been shown to be an effective insecticide against termites (Dugravot et al. 2002) and cockroach species (Dugravot et al. 2003).

Our observation that DMDS and DMTS both in the laboratory and semi-field caused strongly reduced oviposition, confirms work by others who reported oviposition deterrence in the presence of these compounds (Suh et al. 2016). Like in our study, Suh et al. (2016) studied the effect of suboptimal larval habitats of An. coluzzii in a laboratory bioassay and identified DMDS and DMTS in the headspace of water that had been pre-conditioned with late-stage larvae. However, here we show that these compounds also induce deterrence in the semi-field, suggesting the important role of these compounds in natural ecosystems. Sulcatone was also identified in the headspace collections by Suh et al. (2016) and shown to cause oviposition deterrence. Unlike DMDS and DMTS, in the present study sulcatone was not identified to be significantly associated with the presence of mosquito larvae. The difference in results between Suh et al. (2016) and our study is likely to be due to different rearing conditions. It is interesting that capitate peg sensilla of An. coluzzii were activated when exposed to DMDS, DMTS and sulcatone, providing physiological indications that the oviposition deterrence is mediated by the olfactory system (Suh et al. 2016).

With the exception of 2,4-PD, optimal dose ranges for an effect on oviposition were lower than $10^{-10} \mathrm{M}$. For nonane, a dose of $10^{-7} \mathrm{M}$ produced a lower oviposition response, while that of $5.5 \times 10^{-9} \mathrm{M}$ was highly attractive. The dose ranges of DMDS and DMTS with most effect on oviposition were between $10^{-7} \mathrm{M}$ and $10^{-9} \mathrm{M}$, which was in the same range as reported by Suh et al. (2016). The dose-response results demonstrate that testing doses over a wide range is crucial for assessing the potential impact on behavior.

The results of the dual-choice tests with the individual chemicals in the laboratory did not match those from the semi field, where nonane and 2,4-DP elicited high oviposition, and 
DMDS and DMTS suppressed oviposition. As the results with the controls in the laboratory study were highly skewed, and the experimental sets produced outcomes with high standard errors, it is possible that positioning of the experimental cages may have caused a bias in the results. As most females exposed to nonane and 2,4-DP laid eggs, similar to the controls, and females exposed to DMDS and DMTS expressed high egg retention, we conclude that the tested chemicals affected the oviposition behavior in the same way as observed in the semi field study.

The presence of the oviposition attractants nonane and 2,4DP in the headspace of water bodies containing both larval stages, and the repellents DMDS and DMTS in those containing older larvae only, suggests that the positive effect of compounds emitted by first instars is masked by DMDS and DMTS in fourth instars. The masking effect of chemical compounds has been suggested in host-seeking Ae. aegypti females by Logan et al. (2008), and for An. gambiae (including both siblings An. coluzzii and An. gambiae s.s.) serves as a mechanism to prevent oviposition where late-stage larvae are present. Given the close genetic relationship between the members of the An. gambiae complex, the data suggest that these oviposition-mediating chemicals are present in the entire complex.

Our results show that oviposition by An. gambiae is influenced by chemical compounds associated with conspecific larvae and that the oviposition response is dependent on the stage of the larvae present in the oviposition site. The behavior of mosquitoes in response to larvae present in oviposition sites is consistent with the behavior described in our earlier study (Mwingira et al. 2019). Early-stage larvae attract gravid mosquitoes that oviposit, whereas late-stage larvae repel them, and both behaviors are mediated by infochemicals, nonane and 2,4-DP as oviposition stimulants, and DMDS and DMTS as repellents. This phenomenon may affect larval site selection strategies within mosquito populations and could have an important biological effect on mosquito populations such as competition between species (Koenraadt and Takken 2003). It has been found that larvae of different females of $A n$. gambiae were sharing the same habitats, suggesting aggregation by different parent mosquitoes (Chen et al. 2006; Chen et al. 2008). Oviposition sites contain a spectrum of factors influencing oviposition behavior like water type (Sumba et al. 2008), food quality and quantity (Munga et al. 2006). The role of conspecific larvae and other biotic or abiotic factors in oviposition site selection needs to be further explored. Evasion of habitats with L4 larvae by gravid females in the field has not been reported to date.

In conclusion, our results indicate that the attractive effects of chemicals associated with early-stage larvae are cancelled out by the chemicals that are associated with late-stage larvae, presumably DMDS and DMTS. Nonane and 2,4-DP, identified in the headspace of anopheline larvae, elicited a strong oviposition response under semi-field conditions. To our knowledge, this is the first report of identified oviposition attractants associated with anopheline larvae in-vivo. Our observation that conspecific larvae and chemicals associated with them mediate oviposition behavior warrants further studies, especially under field situations. Compounds with a positive effect on breeding-site selection are interesting as potential candidates for applications in ovitraps (Paz-Soldan et al. 2016). The combined use of nonane and/or 2,4-PD and DMDS and/or DMTS in traps can provide a push-pull system, in which mosquitoes are repelled by DMDS and/or DMTS volatilized from dispensers placed in the vicinity of houses and attracted by nonane and/or 2,4-PD, applied in traps positioned just outside of villages.

Acknowledgements We thank Roland Mumm for advice on volatile collection and GC-MS analysis. The mass-rearing of mosquitoes by Frans van Aggelen, André Gidding and Leo Koopman is gratefully acknowledged. Staffs of the Amani Medical Research Centre in Muheza, Tanzania are thanked for their assistance with colony rearing and maintenance of the mosquito spheres. This work was supported by funds from Wageningen University, Project No: 55510 and the Dutch Organisation for Internationalisation in Education (Nuffic) and is published with permission from the Director General, National Institute for Medical Research, Tanzania.

Open Access This article is licensed under a Creative Commons Attribution 4.0 International License, which permits use, sharing, adaptation, distribution and reproduction in any medium or format, as long as you give appropriate credit to the original author(s) and the source, provide a link to the Creative Commons licence, and indicate if changes were made. The images or other third party material in this article are included in the article's Creative Commons licence, unless indicated otherwise in a credit line to the material. If material is not included in the article's Creative Commons licence and your intended use is not permitted by statutory regulation or exceeds the permitted use, you will need to obtain permission directly from the copyright holder. To view a copy of this licence, visit http://creativecommons.org/licenses/by/4.0/.

\section{References}

Allan SA, Kline DL (1995) Evaluation of organic infusions and synthetic compounds mediating oviposition in Aedes albopictus and Aedes aegypti (Diptera: Culicidae). J Chem Ecol 21:1847-1860

Antonov L (2013) Antonov PL [ed.] Tautomerism; Methods and Theories. John Wiley and sons, New York

Asmare Y, Hill SR, Hopkins RJ, Tekie H, Ignell R (2017) The role of grass volatiles on oviposition site selection by Anopheles arabiensis and Anopheles coluzzii. Malaria J 16:65

Bentley MD, Day JF (1989) Chemical ecology and behavioral aspects of mosquito oviposition. Annu Rev Entomol 34:401-421

Bernier UR, Kline DL, Schreck CE, Yost RA, Barnard DR (2002) Chemical analysis of human skin emanations: comparison of volatiles from humans that differ in attraction of Aedes aegypti (Diptera: Culicidae). J Am Mosq Control Assoc 18:186-195

Blackwell A, Johnson SN (2000) Electrophysiological investigation of larval water and potential oviposition chemoattractants for 
Anopheles gambiae sensu stricto. Ann Trop Med Parasit 94:389398

Chen H, Fillinger U, Yan G (2006) Oviposition behavior of female Anopheles gambiae in western Kenya inferred from microsatellite markers. Am J Trop Med Hyg 75:246-250

Chen H, Minakawa N, Cui LW, Yan G (2008) Conspecific sharing of breeding sites by anopheline female mosquitoes (Diptera : Culicidae) inferred from microsatellite markers. J Insect Behav 21: 24-33

Coetzee M, Hunt RH, Wilkerson R, Della Torre A, Coulibaly MB, Besansky NJ (2013) Anopheles coluzzii and Anopheles amharicus, new members of the Anopheles gambiae complex. Zootaxa. 3619: 246-274

Drijfhout F, Kather R, Martin SJ (2009) The role of cuticular hydrocarbons in insects. In: Zhang W, Liu H (eds). Behavioural and Chemical Ecology. Nova Science Publishers Inc., Hauppauge, NY, USA Chapter 3

Du Y, Millar JG (1999) Oviposition responses of gravid Culex quinquefasciatus and Culex tarsalis to bulrush (Schoenoplectus acutus) infusions. J Am Mosq Contr Assoc 15:500-509

Dugassa S, Lindh JM, Lindsay SW, Fillinger U (2016) Field evaluation of two novel sampling devices for collecting wild oviposition site seeking malaria vector mosquitoes: OviART gravid traps and squares of electrocuting nets. Parasit Vectors 9:272

Dugravot S, Sanon A, Thibout E, Huignard J (2002) Susceptibility of Callosobruchus maculatus (Coleoptera: Bruchidae) and its parasitoid Dinarmus basalis (Hymenoptera: Pteromalidae) to Sulphurcontaining compounds: consequences on biological control. Environ Entomol 31:50-557

Dugravot S, Grolleau F, Macherel D, Rochetaing A, Hue B, Stankiewicz M, Huignard J, Lapied B (2003) Dimethyl disulfide exerts insecticidal neurotoxicity through mitochondrial dysfunction and activation of insect KATP channels. J Neurophysiol 90:259-270

Eneh LK, Okal MN, Borg-Karlson AK, Fillinger U, Lindh JM (2016a) Gravid Anopheles gambiae sensu stricto avoid ovipositing in Bermuda grass hay infusion and it's volatiles in two choice eggcount bioassays. Malar J 15:276

Eneh LK, Saijo H, Borg-Karlson AK, Lindh JM, Rajarao GK (2016b) Cedrol, a malaria mosquito oviposition attractant is produced by fungi isolated from rhizomes of the grass Cyperus rotundus. Malar J 15:478

Fritz ML, Huang J, Walker ED, Bayoh MN, Vulule J, Miller JR (2008) Ovipositional periodicity of caged Anopheles gambiae individuals. J Circad Rhythms 6:2

Ganesan K, Mendki MJ, Suryanarayana MVS, Prakash S, Malhotra RC (2006) Studies of Aedes aegypti (Diptera : Culicidae) ovipositional responses to newly identified semiochemicals from conspecific eggs. Aust J Entomol 45:75-80

Gibbs AG (1998) The role of lipid physical properties in lipid barriers. Am Zool 38:268-279

Herrera-Varela M, Lindh JM, Lindsay SW, Fillinger U (2014) Habitat discrimination by gravid Anopheles gambiae sensu lato - a pushpull system. Malar J 13:133

Hölldobler B, Wilson EO (2009) The super-organism, the beauty, elegance, and strangeness of insect societies, W. W. Norton \& Company Ltd., New York

Huang J, Miller JR, Chen SC, Vulule JM, Walker ED (2006) Anopheles gambiae (Diptera: Culicidae) oviposition in response to agarose media and cultured bacterial volatiles. J Med Entomol 43:498-504

Khoga JM, Toth E, Marialigeti K, Borossay J (2002) Fly-attracting volatiles produced by Rhodococcus fascians and Mycobacterium aurum isolated from myiatic lesions of sheep. J Microbiol Meth 48:281-287

Knight JC, Corbet SA (1991) Compounds affecting mosquito oviposition: structure-activity relationships and concentration effects. J Am Mosq Control Assoc 7:37-41
Knols BG, Njiru BN, Mathenge EM, Mukabana WR, Beier JC, Killeen GF (2002) MalariaSphere: a greenhouse-enclosed simulation of a natural Anopheles gambiae (Diptera: Culicidae) ecosystem in western Kenya. Malar J 1:19

Koenraadt CJM, Takken W (2003) Cannibalism and predation among larvae of the Anopheles gambiae complex. Med Vet Entomol 17: $61-66$

Kramer WL, Mulla MS (1979) Oviposition attractants and repellents of mosquitoes: oviposition responses of Culex (Ditera: Culicidae) mosquitoes to organic infusions. Environ Entomol 8:1111-1117

Li YJ, Su XH, Zhou GF, Zhang H, Puthiyakunnon S, Shuai SF, Cai SW, Gu JB, Zhou XH, Yan GY, Chen XG (2016) Comparative evaluation of the efficiency of the BG-sentinel trap, CDC light trap and mosquito-oviposition trap for the surveillance of vector mosquitoes. Parasit Vectors 9:446

Lindh JM, Kannaste A, Knols BGJ, Faye I, Borg-Karlson AK (2008) Oviposition responses of Anopheles gambiae s.s. (Diptera: Culicidae) and identification of volatiles from bacteria-containing solutions. J Med Entomol 45:1039-1049

Lindh JM, Okal MN, Herrera-Varela M, Borg-Karlson AK, Torto B, Lindsay SW, Fillinger U (2015) Discovery of an oviposition attractant for gravid malaria vectors of the Anopheles gambiae species complex. Malar J 14:119

Logan JG, Birkett MA, Clark SJ, Powers S, Seal NJ, Wadhams LJ, Mordue AJ, Pickett JA (2008) Identification of human-derived volatile chemicals that interfere with attraction of Aedes aegypti mosquitoes. J Chem Ecol 34:308-322

Mboera LEG, Takken W, Mdira KY, Chuwa GJ, Pickett JA (2000a) Oviposition and behavioral responses of Culex quinquefasciatus to skatole and synthetic oviposition pheromone in Tanzania. J Chem Ecol 26:1193-1203

Mboera LEG, Takken W, Mdira KY, Pickett JA (2000b) Sampling gravid Culex quinquefasciatus (Diptera: Culicidae) in Tanzania with traps baited with synthetic oviposition pheromone and grass infusions. J Med Entomol 37:172-176

Moore JG, Jessop LD, Osborne DN (1987) Gas-chromatographic and mass-spectrometric analysis of the odor of human feces. Gastroenterol 93:1321-1329

Munga SN, Minakawa N, Zhou G, Barrack OOJ, Githeko AK, Yan G (2006) Effects of larval competitors and predators on oviposition site selection of Anopheles gambiae sensu stricto. J Med Entomol 43: 221-224

Mwingira VS, Spitzen J, Mboera LEG, Torres-Estrada JL, Takken W (2019) The influence of larval stage and density on oviposition site-selection behavior of the Afrotropical malaria mosquito Anopheles coluzzii (Diptera: Culicidae). J Med Entomol. https:// doi.org/10.1093/jme/tjz172

Ogbunugafor CB, Sumba L (2008) Behavioral evidence for the existence of a region-specific oviposition cue in Anopheles gambiae s.s. J Vector Ecol 33:321-324

Okal MN, Francis B, Herrera-Varela M, Fillinger U, Lindsay SW (2013) Water vapour is a pre-oviposition attractant for the malaria vector Anopheles gambiae sensu stricto. Malar J 12:365

Otieno WA, Onyango TO, Pile MM, Laurence BR, Dawson GW, Wadhams LJ, Pickett JA (1988) A field trial of the synthetic oviposition pheromone with Culex quinquefasciatus say (Diptera: Culicidae) in Kenya. Bull Entomol Res 78:463-478

Paz-Soldan VA, Yukich J, Soonthorndhada A, Giron M, Apperson CS, Ponnusamy L, Schal C, Morrison AC, Keating J, Wesson DM (2016) Design and testing of novel lethal ovitrap to reduce populations of Aedes mosquitoes: community-based participatory research between industry, academia and communities in Peru and Thailand. PLoS One 11:e0160386

Perich MJ, Kardec A, Braga IA, Portal IF, Burge R, Zeichner BC, Brogdon WA, Wirtz RA (2003) Field evaluation of a lethal ovitrap against dengue vectors in Brazil. Med Vet Entomol 17:205-210 
Pickett JA (1990) Gas chromatography-mass spectrometry in insect pheromone identification: three extreme case histories. In: Mccaffery AR, Wilson ID (eds) Chromatography for isoltaion of insect hormones and pheromones, pp 299-309

Ponnusamy L, Schal C, Wesson DM, Arellano C, Apperson CS (2015) Oviposition responses of Aedes mosquitoes to bacterial isolates from attractive bamboo infusions. Parasit Vectors 8:486

Rinker DC, Pitts RJ, Zhou X, Suh E, Rokas A, Zwiebel LJ (2013) Blood meal-induced changes to antennal transcriptome profiles reveal shifts in odor sensitivities in Anopheles gambiae. Proc Natl Acad Scie USA 110:8260-8265

Santana AL, Roque RA, Eiras AE (2006) Characteristics of grass infusions as oviposition attractants to Aedes (Stegomyia) (Diptera: Culicidae). J Med Entomol 43:214-220

Soler R, Harvey JA, Kamp AFD, Vet LEM, Van der Putten WH, Van Dam NM, Stuefer JF, Gols R, Hordijk CA, Bezemer TM (2007) Root herbivores influence the behaviour of an aboveground parasitoid through changes in plant-volatile signals. Oikos 116:367-376

Stensmyr MC, Urru I, Collu I, Celander M, Hansson BS, Angioy AM (2002) Rotting smell of dead-horse arum florets. Nature 420:625626

Suh E, Choe DH, Saveer AM, Zwiebel LJ (2016) Suboptimal larval habitats modulate oviposition of the malaria vector mosquito Anopheles coluzzii. PLoS One 11:e149800
Sumba LA, Guda TO, Deng AL, Hassanali A, Beier JC, Knols BGJ (2004) Mediation of oviposition site selection in the African malaria mosquito Anopheles gambiae (Diptera: Culicidae) by semiochemicals of microbial origin. Int J Trop Insect Sc 24:260-295

Sumba LA, Ogbunugafor CB, Deng AL, Hassanali A (2008) Regulation of oviposition in Anopheles gambiae s.s.: role of inter- and intraspecific signals. J Chem Ecol 34:1430-1436

Takken W, Klowden MJ, Chambers GM (1998) Effect of body size on host seeking and blood meal utilization in Anopheles gambiae sensu stricto (Diptera: Culicidae): the disadvantage of being small. J Med Entomol 35:639-645

Takken W, Smallegange RC, Vigneau AJ, Johnston V, Brown M, Mordue-Luntz AJ, Billingsley PF (2013) Larval nutrition differentially affects Plasmodium infection in Anopheles gambiae and Anopheles stephensi. Parasit Vectors 6:345

Wondwosen B (2016) The Identification of cereal volatile compounds that attract gravid malaria mosquito, Anopheles arabiensis Patton (Diptera: Culicidae). PhD thesis, Addis Ababa University Addis Ababa

Wondwosen B, Hill SR, Birgersson G, Seyoum E, Tekie H, Ignell R (2017) A(maize)ing attraction: gravid Anopheles arabiensis are attracted and oviposit in response to maize pollen odours. Malar J $16: 39$ 